\title{
Infection-related immunoglobulin A nephropathy or IgA-dominant postinfectious glomerulonephritis; what is in a name?
}

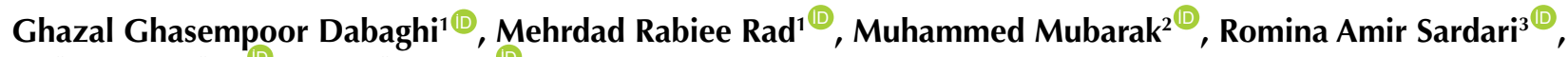 \\ Golnaz K Holm ${ }^{\mathbb{1}}$, Hamid Nasri ${ }^{1 * \mathbb{1}}$
}

${ }^{1}$ Nickan Research Institute, Isfahan, Iran

${ }^{2} J a v e d$ I Kazi Department of Histopathology, Sindh Institute of Urology and Transplantation (SIUT), Karachi, Pakistan

${ }^{3}$ Doctor of Pharmacy, Student at the University of British Columbia, Canada

${ }^{4}$ Independent Researcher, B35 Al Qurm Complex, Abu Dhabi, United Arab Emirates

\section{Correspondence to: \\ Prof. Hamid Nasri, Email: \\ hamidnasri@yahoo.com \\ Received: 10 Feb. 202 \\ Accepted: 11 June 2021 \\ ePublished: 8 July 2021}

Keywords: Glomerulonephritis, IgA nephropathy, Infection, Postinfectious glomerulonephritis Staphylococcus

\begin{abstract}
Immunoglobulin A nephropathy (IgAN) is the most common glomerulonephritis worldwide. However, its incidence and prevalence vary depending on racial and geographical factors. IgAN is a highly heterogeneous disease with wide clinical and pathological variability. The defining and consistent feature of IgAN is the dominance or co-dominance of IgA deposits in the glomeruli on immunofluorescence (IF) microscopy. However, recent reports suggest that a number of post-infectious glomerulonephritis (PIGN) cases also exhibit dominance or co-dominance of IgA deposits on IF microscopy. Therefore, a debate has arisen on labeling these cases either as infection-related IgAN (a form of secondary IgAN) or IgA-dominant PIGN. Although the majority favors the later nosology, this issue has remained unresolved, as is the issue of labelling this condition as PIGN when, in fact, the infection is often intercurrent, and no latent period is found in this condition. This brief narrative review aims to discuss the salient features of this condition and issues related to its nomenclature.
\end{abstract}

Introduction

Immunoglobulin A nephropathy (IgAN) (Berger's Disease in France) is the most common chronic glomerulonephritis and a frequent cause of kidney failure. It was first described by Berger and Hinglais in 1968 (1). Mesangial deposits of IgA1 along with IgG and C3 in the glomeruli, proliferation of mesangial cells and increased extracellular matrix are the hallmark findings of IgAN in immunofluorescence (IF) (2). IgAN is more prevalent in Asia than in European countries (45 out of one million/year in Japan compared with 31 per million population in France). This difference might be secondary to a better screening system in Asian countries, early referral to nephrologists, or different biopsy criteria (3).

\section{Pathophysiology}

There are two types of $\operatorname{IgA}$ molecules in human body; IgA1 and $\operatorname{IgA} 2$, which are responsible for the immunity of the digestive and respiratory systems. Serum IgA levels, particularly $\operatorname{IgA} 1$, are increased in patients

\begin{abstract}
Key point
Immunoglobulin A dominant- post-infectious glomerulonephritis is an increasingly recognized variant of PIGN. The differentiation of this disease from primary immunoglobulin A nephropathy is extremely essential as they have different prognosis and treatment options.
\end{abstract}

with IgAN, which can lead to kidney disorders $(4,5)$. However, IgA deposits may also be seen on kidney biopsy in individuals with no evidence of kidney disease. (6) IgAN is considered a systemic disease with frequent relapses that damage the kidney allograft after transplantation (7). Four pathogenetic mechanisms have been proposed in causing renal disease in the setting of IgAN (Figure 1): a) high level of circulating galactosedeficient IgA1 (Gd-IgA1), b) antibody production of IgG or IgA isotype against Gd$\operatorname{IgA} 1$, c) formation of immune complexes and d) deposition of immune complexes in the glomerular mesangium with consequent injury to the glomeruli (8).

Copyright $\odot 2021$ The Author(s); Published by Society of Diabetic Nephropathy Prevention. This is an open-access article distributed under the terms of the Creative Commons Attribution License (http://creativecommons.org/licenses/by/4.0), which permits unrestricted use, distribution, and reproduction in any medium, provided the original work is properly cited. 


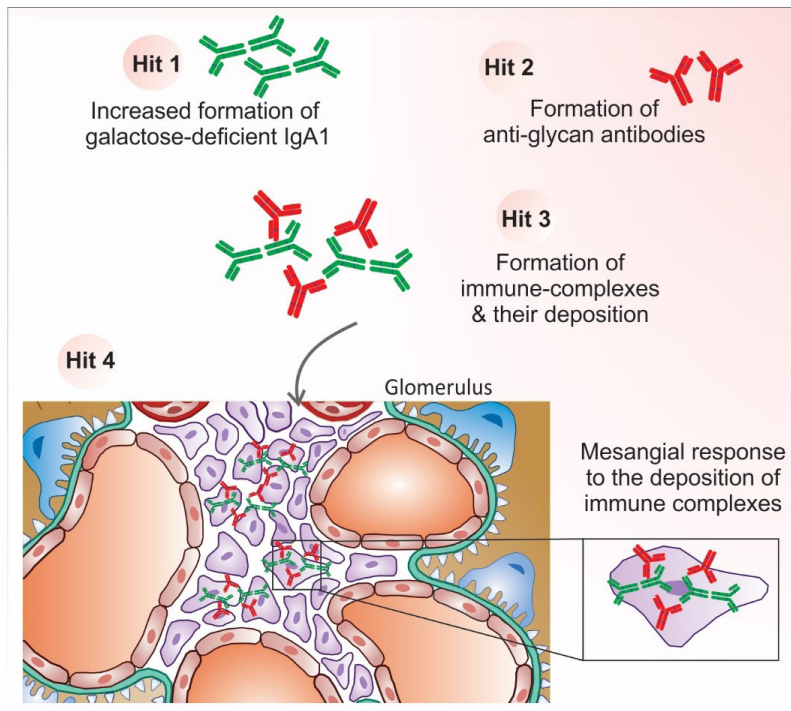

Figure 1. Schematic diagram showing the multi-hit pathogenesis of $\operatorname{IgA}$ nephropathy $(\operatorname{IgAN})$. Not shown are the genetic or epigenetic factors, which may also potentially promote any or all of the other steps in the development of IgAN.

\section{Causes and classification}

The exact cause of IgAN is not known, but it seems that an interplay between genetics, epigenetics, and environmental factors, leads to IgAN development. The role of genetic factors such as some HLA alleles has been proposed, though familial inheritance has not been identified $(9,10)$. Based on etiologic associations, IgAN is broadly categorized into primary and secondary types. There is no distinct histologic difference between primary and secondary IgAN. It is of utmost importance to differentiate between these two types as they have different pathogenesis, clinical courses, and management.

\section{Primary IgAN}

Primary $\operatorname{IgAN}$ is defined by deposition of immunoglobulin (Ig) A in the glomeruli without any distinct causative factors, such as infections or autoimmune inflammatory diseases. Clinically, most patients in the early stages of primary IgAN, exhibit mild signs and symptoms. Variable degrees of microscopic or macroscopic hematuria (34\%), proteinuria (32\%), acute nephritis (10\%), nephrotic syndrome (6\%), acute kidney failure (6\%), and malignant hypertension $(8 \%)$ are common presentations of IgAN $(2,11)$.

\section{Secondary IgAN}

IgAN in the setting of other known diseases, such as infections, liver diseases, celiac disease, intestinal inflammatory diseases, autoimmune diseases such as dermatitis herpetiformis, and colon carcinoma, is categorized as secondary IgAN $(12,13)$. One of the most common causes of secondary IgAN is liver cirrhosis. Kupffer cells are members of the mononuclear phagocyte system that play an important role in the uptake of IgGimmune complexes (IgG-ICs). Sinusoidal endothelial cells are also involved in this clearance mechanism (14). In liver cirrhosis, the asialoglycoprotein receptors decrease on the sinusoidal surfaces of hepatocytes and are localized along the canalicular surfaces (15). The asialoglycoprotein receptor translocation in cirrhotic patients compromises the ICs' uptake and results in their deposition in kidneys and other tissues. Hemminger et al observed a mild to moderate IgA deposition in renal biopsies of $65 \%$ of patients with liver cirrhosis (16). Secondary IgAN presents with clinical presentations of the underlying systemic diseases. It is common in older age and manifests with more hematuria and less hypertension and proteinuria. The treatment of secondary IgAN is directed toward the underlying disease.

\section{Infection-related glomerulonephritis}

Post-infectious glomerulonephritis (PIGN) is usually caused by inflammation that follows an infection. PIGN was first diagnosed in the $18^{\text {th }}$ century, in a patient with scarlet fever (17). Streptococcal, staphylococcal, and gram-negative bacterial infections are the most common causes of infection-related glomerulonephritis $(18,19)$. PIGN develops through different mechanisms, such as the deposition of $\operatorname{IgG}, \mathrm{C} 3$, or rarely, IgA. In recent years, a unique form of infection-related glomerulonephritis has been recognized, which is called IgA dominant PIGN (IgA-PIGN). It has been linked to staphylococcal infection. IgA-PIGN has a predilection for older men, with various comorbidities, mainly diabetes mellitus, but also alcoholism, tumors, or human immunodeficiency virus (HIV) infection (20). It has an unfavorable prognosis as compared to classical PIGN. Differentiation between IgAPIGN and primary IgAN is essential as they have different therapeutic approaches (21). With a growing number of cases of IgA-PIGN, a debate has arisen over classifying this condition as either infection-related $\operatorname{IgAN}$ (a form of secondary IgAN) or IgA-dominant PIGN. Although the majority favors the latter, this issue remains unresolved, as these two are often intercurrent. No latent period occurs in IgA-PIGN in contrast to classical PIGN. In this minireview, we collected data from 13 different case reports including 73 cases of IgA-PIGN and we scrutinized them in terms of demographic, clinical, pathological, and outcome features (Table S1, see Supplementary file 1).

Pathogenesis of infectious-related glomerulonephritis The mechanism of kidney deposition of IgA in infectious patients has not been clearly determined. One of the proposed mechanisms is the production of enterotoxin by staphylococcus, which can function as a super-antigen. Super-antigens, unlike other antigens, can directly bind to MHC II molecules of antigen presenting cells. They can also bind to the variable regions of beta-chains of T-cell receptors (21). The binding of super-antigens to these receptors activates T lymphocytes and consequently stimulates the production of cytokines including 
interleukins 1, 2, 6, and tumor necrosis factor. These cytokines activate B-lymphocytes to produce IgA and IgG (22).

Patients with active tuberculosis have increased level of serum $\operatorname{IgA}$ (23). Mycobacterium tuberculosis antigen triggers T-lymphocytes and increases the production of transforming growth factor-beta 1 (TGF- $\beta 1$ ) (24). Consequently, TGF- $\beta 1$ stimulates B-lymphocytes to differentiate into plasma cells. IgA1 secreted by plasma cells eventually deposits in the kidneys and other tissues (25). The serum level of IgA in diabetic patients is higher due to higher rates of mucosal infections and decreased hepatic clearance (26). These patients are more susceptible to PIGN.

It is well-known that the initial onset of primary IgAN or relapses of a pre-existing primary IgAN may be precipitated by infections, mostly in the upper respiratory tract infections. Such cases have classically been dubbed as 'synpharyngitic glomerulonephritis' based on the lack of a latent period between infection and the development of glomerulonephritis. In addition, the development of IgAN may be promoted by IgA overproduction associated with mucosal infections of the respiratory or gastrointestinal tract. IgAN has also been reported in patients with underlying HIV infection $(27,28)$, in whom IgA immune responses are often exaggerated. Some of the reported cases of post-staphylococcal glomerulonephritis with IgA-dominant or codominant deposits had normal serum complement and showed only mesangial hypercellularity on light microscopy (LM) with no subepithelial deposits on electron microscopy (EM). These cases likely represent examples of primary IgAN (in which an intercurrent infection has caused exacerbation or recurrence of existing glomerulonephritis) rather than true PIGN.

\section{Pathology of IgA-PIGN}

Endocapillary proliferative and exudative glomerulonephritis has been reported as the most common glomerular pattern of injury in IgA-PIGN on LM (Figure 2 ). The second most common pattern was mesangial proliferative glomerulonephritis, which was observed in $41(55.4 \%)$ cases. Crescentic glomerulonephritis was observed in only four percent of patients. In addition, 27\% of patients had more than one glomerular pattern of injury.

The IF study revealed IgA as the dominant Ig in 61 cases (Figure 3), whereas IgM or IgG were found in lesser degrees. The staining for IgA and C3 in 51 cases showed that $33.3 \%$ had co-dominant IgA and C3, while 58.8\% had stronger C3 deposition than IgA. C1q deposits were negative in $65.7 \%$ of cases.

Kappa and lambda light chain depositions were examined in 45 cases. In 27 (60\%) cases, both chains were deposited equally; however, in 16 (35.5\%) cases, lambda light chain staining was dominant. EM study showed that sub-epithelial, sub-endothelial, and mesangial areas were the most common sites of Ig deposition (29-42).

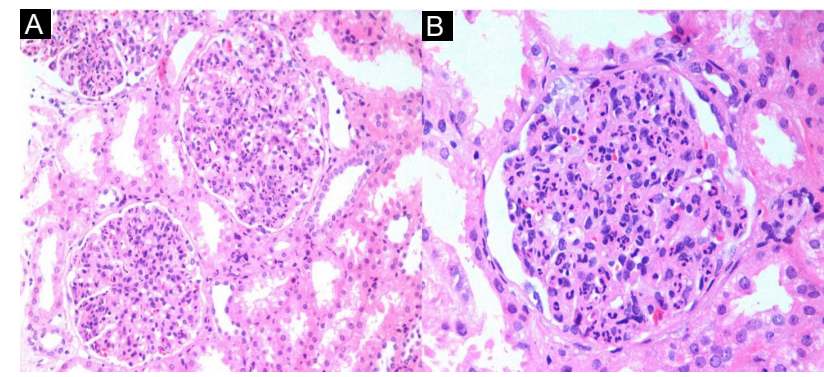

Figure 2. Light microscopy of IgA-dominant postinfectious glomerulonephritis. A. Three glomeruli are shown in this renal biopsy showing global endocapillary hypercellularity and marked obliteration of capillary lumens. (H\&E, ×200). B. Another glomerulus from the same biopsy showing a global endocapillary proliferative and exudative pattern of injury. Capillary lumens are obliterated by endocapillary hypercellularity $(\mathrm{H} \& \mathrm{E}, \times 400)$.

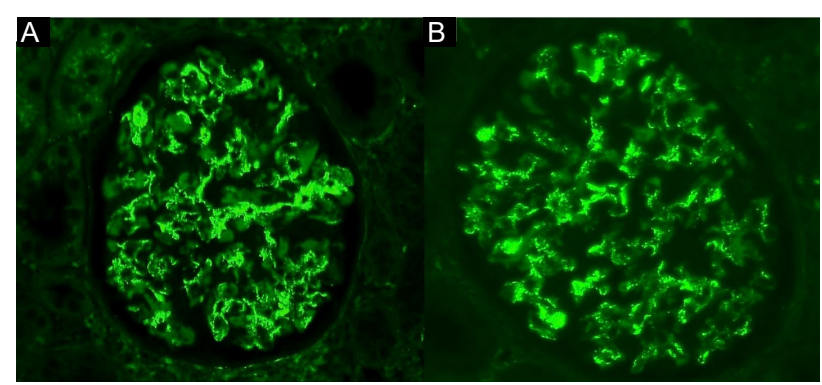

Figure 3. Immunostaining findings in IgA-dominant postinfectious glomerulonephritis. A. There is bright, granular positivity of IgA in the glomerulus: globally in the mesangium and segmentally in the capillary walls. B. C3 is co-dominant and has the same distribution as IgA: globally in the mesangium and segmentally in the capillary walls. (IF, $\times 400)$.

\section{Clinical features}

The clinical features and demographics of 73 cases of IgAPIGN were reviewed. IgA-PIGN was commonly observed in adults and particularly in elderly people, in contrast to typical PIGN, which is a childhood disease. The average age of patients was 57.8 years (range: $16-89$ years). Males suffer from this disease 3.56 times more than females. The most common culprit pathogen was $S$. aureus. The infection with methicillin-resistant Staphylococcus aureus (MRSA) accounted for $43 \%$ of cases and other types of $S$. aureus for $41 \%$. Other pathogens, such as Streptococcus (5.3\%), S. epidermidis (5.3\%), plasmodium falciparum (1.7\%), E. coli (1.7\%), and E. cloacae (1.7\%) have also been observed with lesser frequency. Skin was the most common site of infection, which was reported in $46.7 \%$ of patients. In addition, lung, bone, urinary tract, joints, heart, pharynx, upper respiratory tract, and abscesses were less frequent sites of infection.

Around $45.2 \%$ of cases were previously diagnosed with diabetes mellitus. A range of other diseases such as malignancy, dermatitis, HIV and HCV infection, coronary artery diseases, arterial fibrillation, lipid disorders, and chronic obstructive pulmonary disease were observed in a small number of cases of IgA-PIGN.

The most common clinical presentations were 
hematuria, proteinuria, hypertension, and kidney failure. Proteinuria was observed in all except three cases. The range of proteinuria varied from 0 to $14.5 \mathrm{~g} / \mathrm{d}$ (average: $4.16 \mathrm{~g} / \mathrm{d}$ ). More than $94 \%$ of patients had hematuria. Hypocomplementemia was found in $53 \%$ of cases. Worsening of renal function in the early stages of the disease was a common finding and serum creatinine ranged from 0.8 to $9.5 \mathrm{mg} / \mathrm{dL}$ (average: $2.1 \mathrm{mg} / \mathrm{dL}$ ). Although antibiotics were the cornerstone of treatment, 10 patients received steroids. The type of antibiotics varied depending on the type of pathogens and conditions. Vancomycin, oxacillin, cefazolin, and sulfadoxine/pyrimethamine were prescribed. The outcome of treatment in 70 patients was as follows: 28 (40\%) patients ended up on hemodialysis, 22 (31\%) recovered, 18 (25\%) developed chronic kidney disease (CKD), and two (2.8\%) patients died (29-41).

\section{Conclusion}

IgA-PIGN is an increasingly recognized variant of PIGN. The differentiation of this disease from primary IgAN is extremely essential as they have different prognosis and treatment options. IgA-PIGN develops mostly in elderly, diabetic males after infection with $S$. aureus, hematuria, proteinuria, and hypocomplementemia are observed in most patients. A kidney biopsy is recommended for confirmation of diagnosis and ruling out other types of glomerulonephritis. IgA deposition in glomeruli is a dominant finding on renal biopsy. Furthermore, in most patients, endocapillary proliferation, kappa, and lambda chains deposition, with negative $\mathrm{C1q}$ staining were seen in renal biopsies. Despite using various antibiotic regimens, most patients need dialysis or develop CKD.

\section{Authors' contribution}

Primary draft by GGD and MR. Extensive edit by MM. RAS and GKH conducted further edit of the paper. Finalization of the manuscript by HN. All authors read and signed the final paper.

\section{Conflicts of interest}

The authors declare that they have no competing interests.

\section{Ethical issues}

Ethical considerations (including plagiarism, data fabrication, double publication) have been completely observed by the authors.

\section{Funding/Support}

None.

\section{Supplementary Materials}

Supplementary file 1 contains Table S1.

\section{References}

1. Berger J, Hinglais N. Les ddpôts intercapillaires d'IgA-IgG [Intercapillary deposits of IgA-lgG]. J Urol Nephrol (Paris). 1968;74:694-5. [French].

2. Tomino Y. Diagnosis and treatment of patients with IgA nephropathy in Japan. Kidney Res Clin Pract. 2016;35:197203. doi: 10.1016/j.krcp.2016.09.001.

3. Schena FP, Nistor I. Epidemiology of IgA Nephropathy: A Global Perspective. Semin Nephrol. 2018;38:435-442. doi: 10.1016/j.semnephrol.2018.05.013.

4. Perše $M$, Večerić-Haler Ž. The Role of IgA in the Pathogenesis of IgA Nephropathy. Int J Mol Sci. 2019;20:6199. doi: 10.3390/ ijms20246199.

5. Mestecky J, Russell MW, Jackson S, Brown TA. The human IgA system: a reassessment. Clin Immunol Immunopathol. 1986;40:105-14. doi: 10.1016/0090-1229(86)90073-5.

6. Suzuki K, Honda K, Tanabe K, Toma H, Nihei H, Yamaguchi Y. Incidence of latent mesangial IgA deposition in renal allograft donors in Japan. Kidney Int. 2003;63:2286-94. doi: 10.1046/j.1523-1755.63.6s.2.x.

7. Ponticelli C, Traversi L, Feliciani A, Cesana BM, Banfi G, Tarantino A. Kidney transplantation in patients with IgA mesangial glomerulonephritis. Kidney Int. 2001;60:1948-54. doi: 10.1046/j.1523-1755.2001.00006.x.

8. Suzuki H, Kiryluk K, Novak J, Moldoveanu Z, Herr AB, Renfrow $\mathrm{MB}$, et al. The pathophysiology of IgA nephropathy. J Am Soc Nephrol. 2011;22:1795-803. doi: 10.1681/ASN.2011050464.

9. Galla JH. Molecular genetics in IgA nephropathy. Nephron. 2001;88:107-12. doi: 10.1159/000045969.

10. Hsu SI, Ramirez SB, Winn MP, Bonventre JV, Owen WF. Evidence for genetic factors in the development and progression of IgA nephropathy. Kidney Int. 2000;57:1818-35. doi: 10.1046/j.1523-1755.2000.00032.x.

11. Rodrigues JC, Haas M, Reich HN. IgA Nephropathy. Clin J Am Soc Nephrol. 2017;12:677-686. doi: 10.2215/CJN.07420716.

12. Obrișcă B, Ștefan G, Gherghiceanu M, Mandache E, Ismail G, Stancu S, et al. "Associated" or "Secondary" IgA nephropathy? An outcome analysis. PLoS One. 2019;14:e0221014. doi: 10.1371/journal.pone.0221014.

13. Saha MK, Julian BA, Novak J, Rizk DV. Secondary IgA nephropathy. Kidney Int. 2018;94:674-681. doi: 10.1016/j. kint.2018.02.030.

14. Skogh T, Blomhoff R, Eskild W, Berg T. Hepatic uptake of circulating $\operatorname{lgG}$ immune complexes. Immunology. 1985;55:585-94.

15. Burgess JB, Baenziger JU, Brown WR. Abnormal surface distribution of the human asialoglycoprotein receptor in cirrhosis. Hepatology. 1992;15:702-6. doi: 10.1002/ hep. 1840150425.

16. Hemminger J, Arole V, Ayoub I, Brodsky SV, Nadasdy T, Satoskar AA. Acute glomerulonephritis with large confluent IgAdominant deposits associated with liver cirrhosis. PLoS One. 2018;13:e0193274. doi: 10.1371/journal.pone.0193274.

17. Zegers RH, Weigl A, Steptoe A. The death of Wolfgang Amadeus Mozart: an epidemiologic perspective. Ann Intern Med. 2009;151(4):274-8, W96-7. doi: 10.7326/0003-4819151-4-200908180-00010.

18. Satoskar AA, Parikh SV, Nadasdy T. Epidemiology, pathogenesis, treatment and outcomes of infection-associated glomerulonephritis. Nat Rev Nephrol. 2020;16:32-50. doi: 10.1038/s41581-019-0178-8.

19. Nasr SH, D'Agati VD. IgA-dominant postinfectious glomerulonephritis: a new twist on an old disease. Nephron Clin Pract. 2011;119:c18-25; discussion c26. doi: 10.1159/000324180.

20. Nasr SH, Radhakrishnan J, D'Agati VD. Bacterial infectionrelated glomerulonephritis in adults. Kidney Int. 2013;83:792803. doi: 10.1038/ki.2012.407.

21. Koyama A, Sharmin S, Sakurai H, Shimizu Y, Hirayama K, Usui J, et al. Staphylococcus aureus cell envelope antigen is a new candidate for the induction of IgA nephropathy. Kidney Int. 2004;66:121-32. doi: 10.1111/j.1523-1755.2004.00714.x.

22. Koo TY, Kim GH, Park MH. Clinicopathologic Features of IgADominant Postinfectious Glomerulonephritis. Korean J Pathol. 2012;46:105-14. doi: 10.4132/KoreanJPathol.2012.46.2.105. 
23. Alifano $M$, Sofia M, Mormile M, Micco A, Mormile AF, Del Pezzo $M$, et al. IgA immune response against the mycobacterial antigen A60 in patients with active pulmonary tuberculosis. Respiration. 1996;63:292-7. doi: 10.1159/000196563.

24. Gossman W, Oldfield E. Quantitative structure--activity relations for gammadelta $\mathrm{T}$ cell activation by phosphoantigens. J Med Chem. 2002;45:4868-74. doi: 10.1021/jm020224n.

25. Lai KN, Ho RT, Leung JC, Lai FM, Li PK. Increased mRNA encoding for transforming factor-beta in CD4+ cells from patients with IgA nephropathy. Kidney Int. 1994;46:862-8. doi: 10.1038/ki.1994.343.

26. Noh JW, Wiggins R, Phan SH. Urine transforming growth factor-beta activity is related to the degree of scarring in crescentic nephritis in the rabbit. Nephron. 1993;63:73-8. doi: 10.1159/000187146.

27. Contreras-Chavez P, Anampa-Guzmán A, Henao J, Fernandez R, Saad P. Not your Typical Rash: A Case of IgA Nephropathy in the Setting of HIV. Cureus. 2019;11:e5368. doi: 10.7759/ cureus.5368.

28. Tada M, Masumoto S, Hinoshita F. Clinical remission of IgA nephropathy in an HIV-positive patient after combined treatment with tonsillectomy and steroid pulse therapy. CEN Case Rep. 2015;4:157-161. doi: 10.1007/s13730-014-0158-6.

29. Nasr SH, Markowitz GS, Whelan JD, Albanese JJ, Rosen RM, Fein DA, et al. IgA-dominant acute poststaphylococcal glomerulonephritis complicating diabetic nephropathy. Hum Pathol. 2003;34:1235-41. doi: 10.1016/s00468177(03)00424-6.

30. Rafieian-Kopaei M, Nasri H, Alizadeh F, Ataei B, Baradaran A. Immunoglobulin A Nephropathy and Malaria falciparum Infection; a Rare Association. Iran J Public Health. 2013;42:529-33.

31. Haas M, Racusen LC, Bagnasco SM. IgA-dominant postinfectious glomerulonephritis: a report of 13 cases with common ultrastructural features. Hum Pathol. 2008;39:130916. doi: 10.1016/j.humpath.2008.02.015.

32. Saad M, Daoud M, Nasr P, Syed R, El-Sayegh S. IgA-dominant post-infectious glomerulonephritis presenting as a fatal pulmonary-renal syndrome. Int J Nephrol Renovasc Dis. 2015;8:77-81. doi: 10.2147/IJNRD.S84061.
33. Long JA, Cook WJ. IgA deposits and acute glomerulonephritis in a patient with staphylococcal infection. Am J Kidney Dis. 2006;48:851-5. doi: 10.1053/j.ajkd.2006.06.015.

34. Nasr SH, Share DS, Vargas MT, D'Agati VD, Markowitz GS. Acute poststaphylococcal glomerulonephritis superimposed on diabetic glomerulosclerosis. Kidney Int. 2007;71:1317-21. doi: $10.1038 /$ sj.ki.5002135.

35. Mandai S, Aoyagi M, Nagahama K, Arai Y, Hirasawa S, Aki S, et al. Post-staphylococcal infection Henoch-Schönlein purpura nephritis: a case report and review of the literature. Ren Fail. 2013;35:869-74. doi: 10.3109/0886022X.2013.794703.

36. Wehbe E, Salem C, Simon JF, Navaneethan SD, Pohl M. IgA-dominant Staphylococcus infection-associated glomerulonephritis: case reports and review of the literature. NDT Plus. 2011;4:181-5. doi: 10.1093/ndtplus/sfr017.

37. Handa $\mathrm{T}$, Ono $\mathrm{T}$, Watanabe $\mathrm{H}$, Takeda $\mathrm{T}$, Muso E, Kita T. Glomerulonephritis induced by methicillin-sensitive Staphylococcus aureus infection. Clin Exp Nephrol. 2003;7:247-9. doi: 10.1007/s10157-003-0240-4.

38. Handa $T$, Kakita $H$, Tateishi $Y$, Endo $T$, Suzuki $H$, Katayama $\mathrm{T}$, et al. The features in IgA-dominant infection-related glomerulonephritis distinct from IgA nephropathy: a singlecenter study. Clin Exp Nephrol. 2018;22:1116-1127. doi: 10.1007/s10157-018-1564-4.

39. Nayer A, Davda G, Pai R, Ortega LM. IgA-dominant postinfectious glomerulonephritis; making another case in support of renal biopsy in type 2 diabetic nephropathy. J Renal Inj Prev. 2016;5:45-7. doi: 10.15171/jrip.2016.10.

40. Satoskar AA, Nadasdy G, Plaza JA, Sedmak D, Shidham G, Hebert L, et al. Staphylococcus infection-associated glomerulonephritis mimicking IgA nephropathy. Clin J Am Soc Nephrol. 2006;1:1179-86. doi: 10.2215/CJN.01030306.

41. Yoh K, Kobayashi M, Hirayama A, Hirayama K, Yamaguchi $\mathrm{N}$, Nagase $\mathrm{S}$, et al. A case of superantigen-related glomerulonephritis after methicillin-resistant Staphylococcus aureus (MRSA) infection. Clin Nephrol. 1997;48:311-6.

42. Cohen AJ, Rosenstein ED. IgA nephropathy associated with disseminated tuberculosis. Arch Intern Med. 1985;145:554-6. 